\title{
A procedure for the evaluation of the historical trend of atmospheric pollution in an urban area
}

\author{
F. Murena ${ }^{1} \&$ M. Urciuolo ${ }^{2}$ \\ ${ }^{I}$ Chemical Engineering Department, University of Naples \\ "Federico II", Italy \\ ${ }^{2}$ Combustion Research Institute CNR, Naples, Italy
}

\begin{abstract}
Air pollution in large urban areas is still a sanitary emergency even though significant improvements have been reached in fuel quality and vehicular emissions. Many air pollutants when inhaled are toxic to humans and can cause threats to the respiratory system and chest congestion and other health problems. The correlation between the concentration of atmospheric pollutants and health impact is not straightforward due to the complexity of atmospheric mixtures and the antagonistic or synergic effects of pollutants. At the same time public authorities need tools for the evaluation of their policies for the mitigation of air pollution. A possible approach to both these problems is the evaluation of historical trends of air pollution in urban areas to be compared with sanitary data or for the evaluation of the effectiveness of environmental policies. In this paper a procedure to evaluate historical trends of air pollution has been developed using air pollution indexes. Data collected by the air monitoring quality network in the urban area of Naples from 2001 to 2007 have been analysed to evaluate three different daily air quality indexes. The different indexes were compared to check the correlation among them. Some correlation exists among the indexes considered but the distribution in the defined risk classes was different. Therefore, the three indexes considered cannot be assumed as equivalent. Only correlation with sanitary data can help to select which index is the most apt. A statistical analysis was then developed to obtain an historical trend of air pollution in Naples. Even though there were some differences, all indexes show that from 2001 to 2007 the air quality in Naples has, on average, improved.

Keywords: atmospheric pollution, index, urban area, trend, statistics.
\end{abstract}




\section{Introduction}

To characterize the quality of the air at a given location, government agencies elaborate data from air quality monitoring stations to calculate numerical indexes named air pollution indexes (API) or air quality indexes (AQI). The aim of each index is to synthesise local atmospheric pollution, due to concentration of several pollutants expressed with different units, in a single number. In this way risks associated with local atmospheric pollution and behaviours to be followed to minimize the impact on human health can be effectively communicated to population. Several procedures are reported in literature to calculate these indexes. In the USA the Air Quality Index (AQI) of Environmental Protection Agency (EPA) (EPA [1]) is the standard. In Europe there is not a single index adopted by all the countries, but the single nations or the local authorities adopt their own index. Several indexes are proposed and reported in literature: Albergamo et al. [2]; Cheng et al. [3]; Cogliani [4]; Guzzi [5]; Kassomenos et al. [6]; Murena [7]. In this paper three different indexes have been considered: CAQI (Common air quality index); APHI (Air Pollution Health Index) and AQHI (Air Quality Health Index). All are daily indexes. It means that their value would be representative of the atmospheric pollution in a solar day. The Common Air Quality Index (CAQI) was developed in the CiteAir project (http://www.citeair.eu). It belongs to the category of Air Pollution Indexes and is based on limit values of the European legislation EC [8-10]. In the same category belong, with some peculiarities, other indexes like: Air quality Index (AQI) of the US Environmental Protection Agency (www.epa.gov) [10]; ATMO adopted in France (http://www.airparif.asso.fr) and UK-AQI adopted in UK (http://www.airquality.co.uk). The CAQI is a daily index with values in the range $0-100$ subdivided in 5 classes. CAQI procedure defines two different categories of stations: traffic and city background. For the first category mandatory pollutants are $\mathrm{NO}_{2}$ and $\mathrm{PM} 10$, for the second one $\mathrm{O}_{3}$ is added. For this study the two categories have been merged.

Table 1: $\quad$ Pollutants and calculation grid adopted for calculation of CAQI index. All concentrations are in $\mu \mathrm{g} / \mathrm{m}^{3}$. Daily representative values of concentration are: $\mathrm{NO}_{2}$ and $\mathrm{O}_{3}$ maximum hourly value; $\mathrm{CO} 8$ maximum hours moving average and PM10 daily average.

\begin{tabular}{|c|c|c|c|c|c|c|}
\hline $\begin{array}{c}\text { Class of } \\
\text { risk }\end{array}$ & $\begin{array}{c}\text { Index } \\
\text { value }\end{array}$ & $\mathrm{NO}_{2}$ & $\begin{array}{c}\text { PM10 } \\
1 \text { hour }\end{array}$ & $\begin{array}{c}\text { PM10 } \\
24 \text { hours }\end{array}$ & $\mathrm{O}_{3}$ & $\mathrm{CO}$ \\
\hline Very & $0-25$ & $0-50$ & $0-25$ & $0-12$ & $0-60$ & $0-5000$ \\
\hline Low & $26-50$ & $51-100$ & $26-50$ & $13-25$ & $61-120$ & $5001-7500$ \\
\hline Medium & $51-75$ & $101-200$ & $51-90$ & $26-50$ & $121-$ & $7501-$ \\
& & & & 180 & 10000 \\
\hline High & $76-100$ & $201-400$ & $91-180$ & $51-100$ & $181-$ & $10001-$ \\
& & & & & 240 & 20000 \\
\hline Very & $>100$ & $>400$ & $>180$ & $>100$ & $>240$ & $>20000$ \\
\hline
\end{tabular}


The calculation grid reported in Table 1 has been adopted to evaluate the CAQI index. Values of CAQI index are calculated for each pollutant by linear interpolation from the calculation grid. The daily index of the station is the maximum of the daily indexes calculated for the air pollutants. The Air Pollution Health Index (APHI) was proposed by Cairncross et al. [11] and developed starting from an analysis of the mortality risk associated at each atmospheric pollutant. The index is calculated by summing the contribution of each pollutant by the formula:

$$
A P H I=\sum a_{i} C_{i}
$$

where $a_{i}$ is a coefficient and $C_{i}$ is a value "representative" of the concentration of the pollutant " $\mathrm{i}$ " in the 24 hours considered. Values of $a_{i}$ and $C_{i}$ to be adopted are reported in Table 2. The two values of PM and ozone that can be calculated from Table 2 are in alternative: only the highest must be considered in Eq. (1). Differently from CAQI, APHI has not a ceiling value.

Table 2: Daily representative values of concentration $\left(C_{i}\right)$ and coefficients $\left(a_{i}\right)$ for the calculation of APHI (representative values are all in $\mu \mathrm{g} / \mathrm{m}^{3}$ but $\mathrm{CO}$ in $\mathrm{mg} / \mathrm{m}^{3}$ ).

\begin{tabular}{|c|c|c|}
\hline Pollutant & $\boldsymbol{C}_{\boldsymbol{i}}$ & $\boldsymbol{a}_{\boldsymbol{i}}$ \\
\hline $\mathrm{PM} 10$ & Daily average & 0.048 \\
\hline $\mathrm{PM} 2.5$ & Daily average & 0.10 \\
\hline $\mathrm{SO}_{2}$ & Daily average & 0.026 \\
\hline $\mathrm{O}_{3}$ & max of 8 h mobile average & 0.033 \\
\hline $\mathrm{O}_{3}$ & max of hourly average & 0.03 \\
\hline $\mathrm{NO}_{2}$ & max of hourly average & 0.02 \\
\hline $\mathrm{CO}$ & max of 8 h mobile average & 0.25 \\
\hline
\end{tabular}

The classes of risks are four as reported in Table 3. The Air Quality Health Index, was developed by Stieb et al. [12], and is based on an analysis of mortality data collected in Canada.

Table 3: $\quad$ Classes of risk of APHI and AQHI.

\begin{tabular}{|c|c|c|}
\hline Class of risk & APHI & AQHI \\
\hline Low & $1-3$ & $0-3$ \\
\hline Medium & $4-6$ & $4-6$ \\
\hline High & $7-9$ & $7-10$ \\
\hline Very high & $\geq 10$ & $\geq 10$ \\
\hline
\end{tabular}


It is calculated by the following formula:

$$
\mathrm{AQHI}_{\mathrm{PM} 10}=\frac{10}{11.7}\left(100 \times \mathrm{e}^{0.000871 \cdot \mathrm{NO}_{2}}-1+\mathrm{e}^{0.000537 \cdot \mathrm{O}_{3}}-1+\mathrm{e}^{0.000297 \cdot \mathrm{PM} 10}-1\right)
$$

if data on PM10 are available, or by the formula:

$$
\mathrm{AQHI}_{\mathrm{PM} 2.5}=\frac{10}{10.4}\left(100 \times \mathrm{e}^{0.000871 \cdot \mathrm{NO}_{2}}-1+\mathrm{e}^{0.000537 \cdot \mathrm{O}_{3}}-1+\mathrm{e}^{0.000487 \cdot \mathrm{PM} 2.5}-1\right)
$$

if data on PM2.5 are available. Concentrations are in ppb for $\mathrm{NO}_{2}$ and $\mathrm{O}_{3}$ and in $\mu \mathrm{g} / \mathrm{m}^{3}$ for PM10 and PM2.5. Daily representative values of concentration are: the maximum $3 \mathrm{~h}$ mobile average for $\mathrm{NO}_{2}$ and $\mathrm{O}_{3}$ and the $24 \mathrm{~h}$ average for PM. AQHI, as APHI, does not have a ceiling value and four classes of risk (Table 3).

Both APHI and AQHI deriving from sanitary data belong to the category of "health indexes".

\section{Methodology}

The three pollution indexes considered have been adopted to evaluate air pollution in Naples from 2001 to 2007 . The air quality network in the urban area of Naples is composed of nine fixed monitoring stations. The location of fixed stations is reported in Fig. 1, while a scheme of pollutants monitored by each station is reported in Table 4.

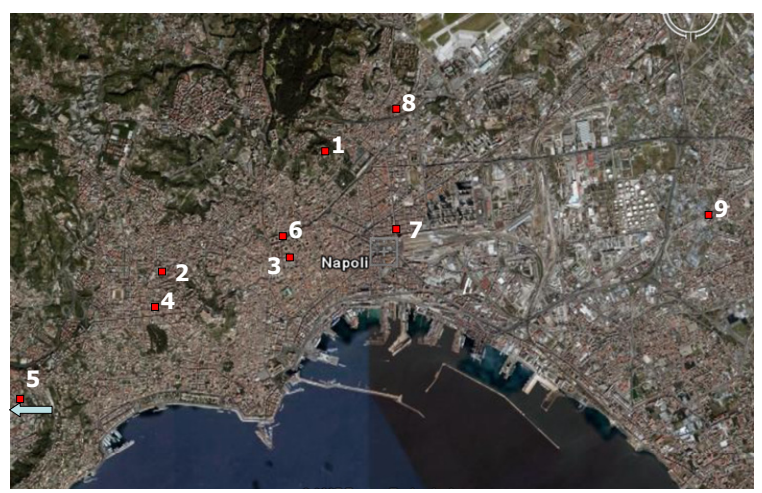

Figure 1: $\quad$ Map of Naples with locations of air quality monitoring stations.

The location criteria and the techniques adopted to monitor air pollutants respect the European directives [9, 10]. The monitoring efficiency was generally high: in many cases above 90\%. The modifications occurred from 2001 to 2007 about the monitoring facilities of the air quality network as reported in Table 4. 
Table 4: Analytical facilities of air quality network of Naples.

\begin{tabular}{|c|c|c|c|c|c|c|c|c|}
\hline$\#$ & & $\mathrm{CO}$ & $\mathrm{NO}_{2}$ & $\mathrm{PTS}$ & $\mathrm{PM} 10$ & $\mathrm{PM} 2.5$ & $\mathrm{O}_{3}$ & $\mathrm{SO}_{2}$ \\
\hline 1 & Oss Astronomico & $\mathrm{X}$ & $\mathrm{X}$ & $\mathrm{X}^{1}$ & $\mathrm{X}^{1}$ & & $\mathrm{X}$ & $\mathrm{X}$ \\
\hline 2 & Santobono & $\mathrm{X}^{1}$ & $\mathrm{X}$ & & $\mathrm{X}^{4}$ & & & $\mathrm{X}^{5}$ \\
\hline 3 & Policlinico $^{1}$ & $\mathrm{X}^{1}$ & $\mathrm{X}$ & & $\mathrm{X}^{5}$ & & & $\mathrm{X}^{5}$ \\
\hline 4 & Fuorigrotta $^{2}$ & $\mathrm{X}$ & $\mathrm{X}$ & & $\mathrm{X}$ & & & \\
\hline 5 & Vanvitelli $^{3}$ & $\mathrm{X}$ & $\mathrm{X}$ & & $\mathrm{X}$ & $\mathrm{X}^{4}$ & & \\
\hline 6 & Cavour $^{3}$ & $\mathrm{X}$ & $\mathrm{X}$ & & & & & \\
\hline 7 & Ferrovia $^{2}$ & $\mathrm{X}$ & $\mathrm{X}$ & & $\mathrm{X}$ & & & \\
\hline 8 & Nuovo Pellegrini & & $\mathrm{X}$ & & & & $\mathrm{X}$ & \\
\hline 9 & Via Argine & & $\mathrm{X}$ & & $\mathrm{X}^{1}$ & & $\mathrm{X}$ & $\mathrm{X}^{1}$ \\
\hline
\end{tabular}

${ }^{1}$ working in $03-07 ;{ }^{2}$ station working only in $02-03$; ${ }^{3}$ station working only 06-07; ${ }^{4}$ working $03-05$ and $07 ;{ }^{5}$ working $02-05$ and 07.

For each of the three indexes considered the procedure to evaluate the daily pollution index in a station is fixed. But in this case we want to evaluate a daily pollution index for a whole urban area not for a single station. Therefore, a specific procedure was defined:

i) daily representative values were calculated and validated for each pollutant and each station;

ii) daily representative value for each pollutant was calculated and validated for the whole urban area;

iii) daily indexes for the whole urban area were calculated and validated on the basis of daily representative values of each pollutant calculated at point ii).

The daily representative values, required by each calculation procedure, are validated if at least $75 \%$ of data mandatory for their evaluation were present.

Table 5 shows in detail the validation criteria adopted.

Table 5: Validation criteria for calculation of representative values.

\begin{tabular}{|c|c|}
\hline Representative values & Minimum number of data for validation \\
\hline $\begin{array}{c}\text { Daily maximum of } \\
\text { hourly average }\end{array}$ & 18 hourly average \\
\hline Daily average & 18 hourly average \\
\hline $\begin{array}{c}\text { Daily maximum of } 8 \mathrm{~h} \\
\text { mobile average }\end{array}$ & $\begin{array}{c}18 \text { values of } 8 \mathrm{~h} \text { mobile average }(6 \text { hourly average } \\
\text { to validate each } 8 \text { hour mobile average })\end{array}$ \\
\hline $\begin{array}{c}\text { Daily maximum of } 3 \mathrm{~h} \\
\text { mobile average }\end{array}$ & $\begin{array}{c}18 \text { values of } 3 \mathrm{~h} \text { mobile average }(2 \text { hourly average } \\
\text { to validate each } 3 \mathrm{~h} \text { mobile average })\end{array}$ \\
\hline
\end{tabular}

Once representative values were calculated for each pollutant and for each station then a representative value of the urban area was calculated for each pollutant as: average or maximum of representative values of all stations. 
In this paper only results corresponding to the first case are reported. Therefore the representative value of concentration of each pollutant for the whole urban area was calculated as average value of the representative values calculated for all stations. The representative value for the whole urban area was assumed valid even in the case of a single representative value validated for all the stations.

Once obtained the representative values of concentration for the whole urban area the calculation of pollution index is straightforward: the procedure defined for each index, and reported before, has to be followed.

Urban area daily pollution indexes have been validated only if representative concentration for all mandatory pollutants were validated for the urban area. To conform the different procedures we have assumed as mandatory pollutants: $\mathrm{NO}_{2}, \mathrm{PM} 10$ and $\mathrm{O}_{3}$.

We have not considered data of PM2.5 because it was measured only at \#5 station and not in all the years (Table 4).

\section{Results}

Comparison of results of the tree indexes selected is not straightforward, essentially because they are different for the scale adopted and for a presence of a ceiling value (CAQI) or its absence (APHI and AQHI). For CAQI if the value of 100 is exceeded the notation $>100$ is adopted. For this reason a first comparison was tested evaluating the frequency of classes of risk for each index reported in Tables 1 and 3. To conform the three indexes the 5 classes of risk of CAQI were reduced to 4 putting together the first two classes associated with the minimum risk. Results are reported in Fig. 2.

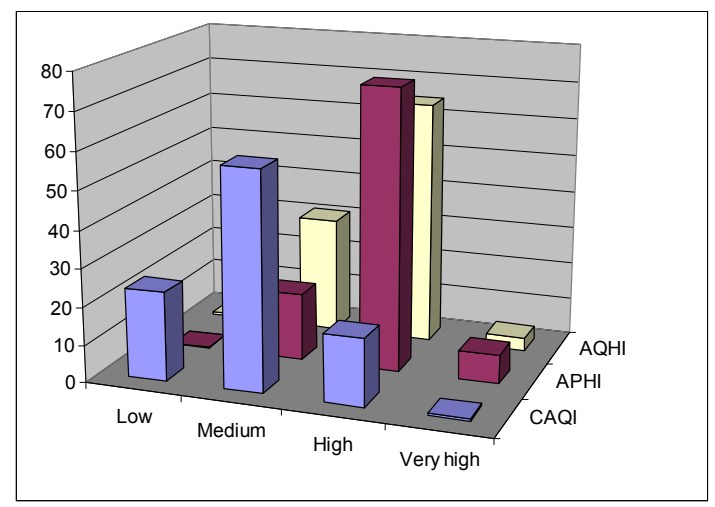

Figure 2: Frequency distribution in risk classes of the air pollution indexes from 2001 to 2007.

There is a significant difference among the indexes. CAQI is characterised by a high frequency of days with a low (24\%) and medium (58\%) class of risk, while the most frequent class for APHI and AQHI is the "high" risk class $75 \%$ 
and $65 \%$ respectively. "Very high" risk class occurs rarely with a frequency of $0.7 \%$ for CAQI, $7.7 \%$ for APHI and $3.6 \%$ for AQHI.

Correlation between the indexes was then studied. As an example results obtained for 2007 are reported in Fig. 3.

2007
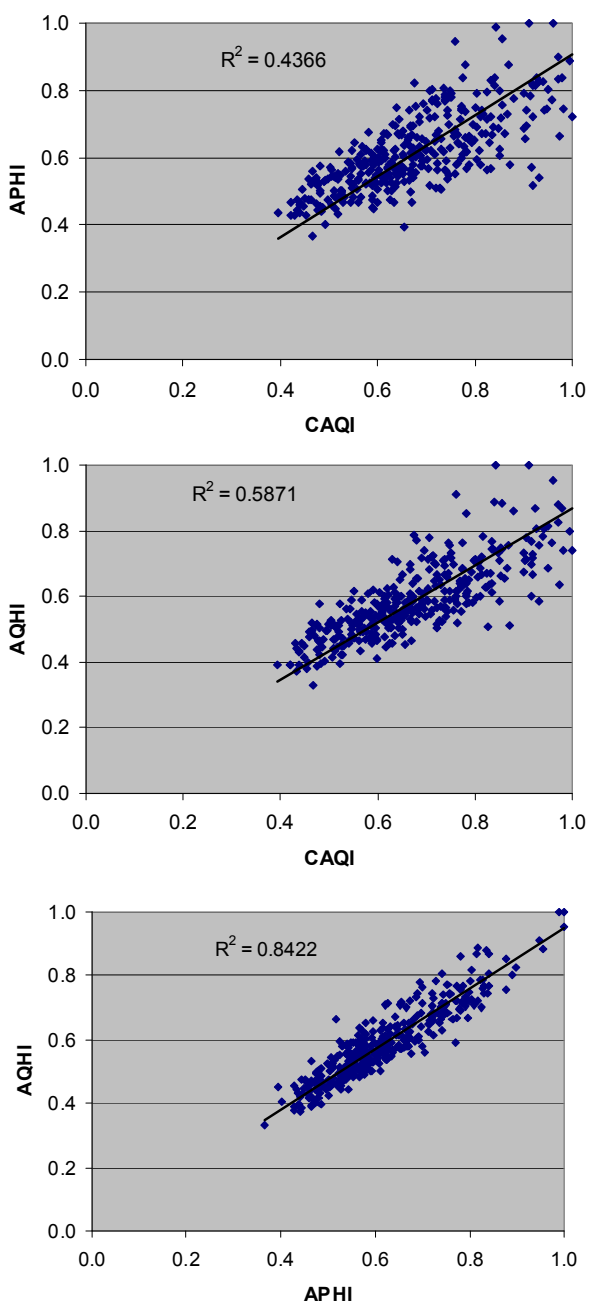

Figure 3: Correlations between indexes for 2007. Values relative to maximum are reported for each index.

The highest correlation was observed between APHI and AQHI (average value $R^{2}=0.81$ ). The lowest between CAQI and APHI (average value $R^{2}=0.40$ ). Determination coefficients obtained are reported in Table 6. 
Table 6: Correlation analysis: determination coefficient $\left(\mathrm{R}^{2}\right)$ between indexes.

\begin{tabular}{|c|c|c|c|}
\hline & CAQI / APHI & CAQI / AQHI & APHI / AQHI \\
\hline 2001 & 0.61 & 0.46 & 0.89 \\
\hline 2002 & 0.63 & 0.67 & 0.87 \\
\hline 2003 & 0.42 & 0.32 & 0.78 \\
\hline 2004 & 0.44 & 0.61 & 0.81 \\
\hline 2005 & 0.10 & 0.46 & 0.77 \\
\hline 2006 & 0.16 & 0.50 & 0.74 \\
\hline 2007 & 0.44 & 0.59 & 0.84 \\
\hline Average & 0.40 & 0.52 & 0.81 \\
\hline
\end{tabular}

A statistical multiple comparison procedure of average yearly index was carried out to analyse the historical trend. On the basis of daily urban index a yearly average urban index was calculated and the trend from 2001 to 2007 of the yearly average index was studied.

In Fig. 4 box and whisker plots are reported for the tree indexes showing the trend of yearly average values. Result of multiple range test are summarised in Table 7. X's in the same column identify years with means of the air quality index that have not statistically significant differences at the $95.0 \%$ confidence level.

Table 7: $\quad$ Results of multiple range test.

\begin{tabular}{|c|c|c|c|c|c|c|c|c|c|c|c|c|c|}
\hline & \multicolumn{5}{|c|}{ CAQI } & \multicolumn{4}{c|}{ APHI } & \multicolumn{5}{c|}{ AQHI } \\
\hline 2001 & & & & & $\mathrm{X}$ & & & & $\mathrm{X}$ & & & & $\mathrm{X}$ \\
\hline 2002 & & $\mathrm{X}$ & $\mathrm{X}$ & & & & $\mathrm{X}$ & & & & & $\mathrm{X}$ & \\
\hline 2003 & & & & $\mathrm{X}$ & & & & $\mathrm{X}$ & & & & $\mathrm{X}$ & \\
\hline 2004 & & & $\mathrm{X}$ & & & & & $\mathrm{X}$ & & & $\mathrm{X}$ & & \\
\hline 2005 & $\mathrm{X}$ & & & & & & $\mathrm{X}$ & & & $\mathrm{X}$ & & & \\
\hline 2006 & $\mathrm{X}$ & & & & & & $\mathrm{X}$ & & & & $\mathrm{X}$ & & \\
\hline 2007 & $\mathrm{X}$ & $\mathrm{X}$ & & & & $\mathrm{X}$ & & & & & $\mathrm{X}$ & & \\
\hline
\end{tabular}

Also in this case the three index show different results. Some common results can be, however, highlighted. The yearly average of 2001 has a statistically significant difference with average of other years in all the three cases (it is the most polluted year). For all the three indexes 2005, 2006 and 2007 are the three less polluted years. More in detail the less polluted years are: 2005, 2006 and 2007 for CAQI (the difference is not statistically significant); 2007 for APHI and 2005 for AQHI. 2003 is the second highest polluted year for all the three indexes (together with 2004 for APHI or 2002 for AQHI). 2002 is the second (APHI and $\mathrm{AQHI})$ or the third (CAQI) highest polluted year. 
Therefore, it can be concluded that apart from the differences in the pollution indexes considered a decreasing trend for air pollution in Naples from 2001 to 2007 can be observed.
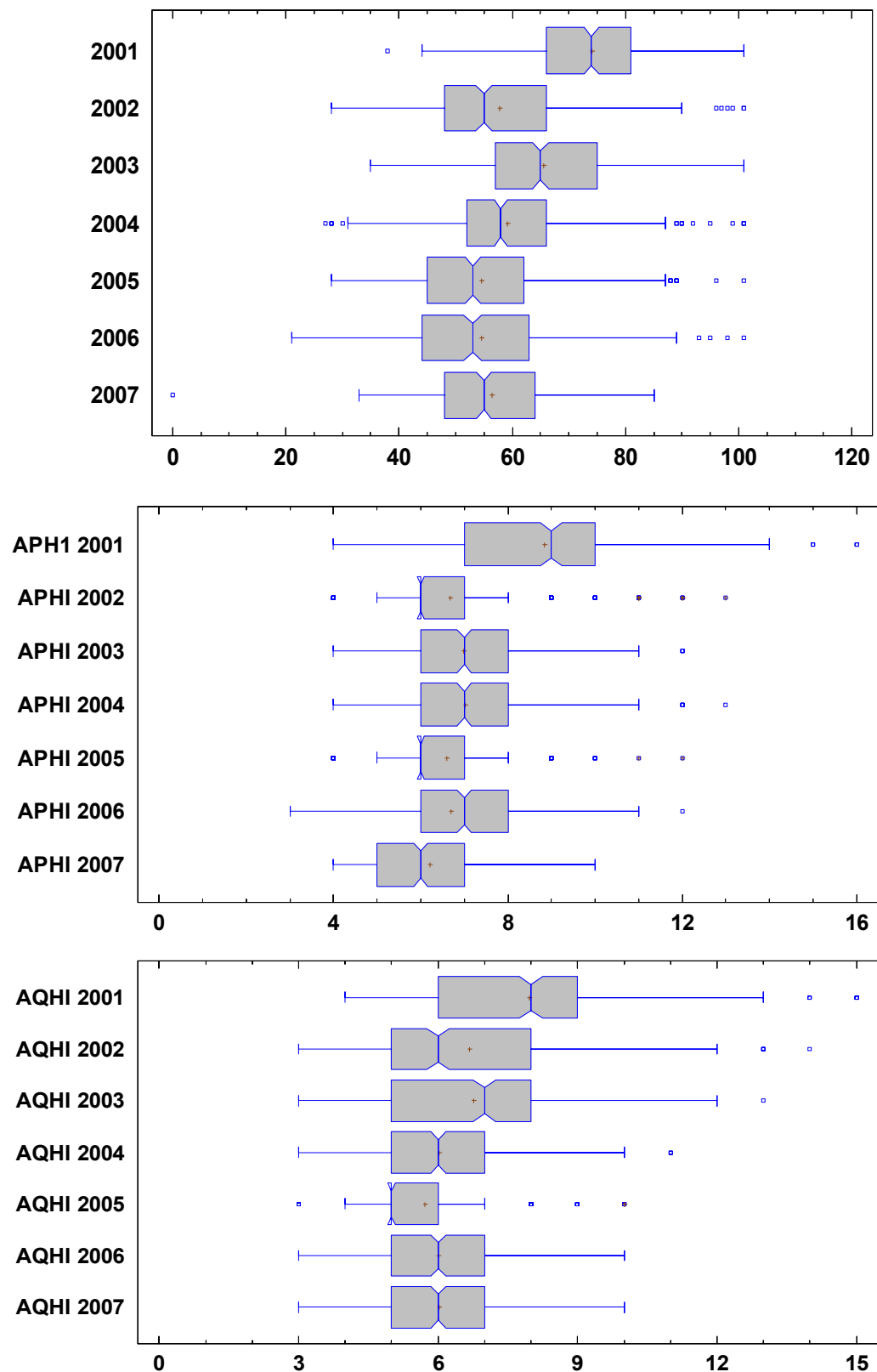

Figure 4: Box and whisker plot for the three indexes showing the trend from 2001 to 2007. 


\section{Conclusions}

The procedure developed allows the evaluation of historical trend of air pollution in urban areas. This goal was obtained using air pollution indexes. The final result depends on the pollution index adopted. In the case of Naples data from 2001 to 2007 show a certain decrease of air pollution. APHI and AQHI indexes are more similar and correlated. CAQI gives more different results. The final decision on the most apt index to be adopted can be taken only after that a analysis of correlation with sanitary data has been carried out. In such analysis it is necessary to take in count that any sanitary data are not exclusively determined by the air pollution levels, but also by many other social, demographical and infrastructural factors.

\section{References}

[1] Environmental Protection Agency, 1999. Guideline for reporting of daily air quality - air quality index (AQI). EPA-454/R-99-010. Office of Air Quality Planning and Standards, Research Triangle Park, NC 27711.

[2] Albergamo, C., Cagnetti, P., Mammarella, M.C., Tondo, A., 1996. Indice giornaliero della qualità dell'aria:IGQA. ENEA Casaccia Italy.

[3] Cheng, W., Kuo,Y., Lin,P., Chang, K., Chen, Y., Lin, T., Huang, R., 2004. Revised air quality index derived from an entropy function. Atmospheric Environment 38, 383-391.

[4] Cogliani, E., 2001. Air pollution forecast in cities by an air pollution index highly correlated with meteorological variables. Atmospheric Environment $35,2871-2877$.

[5] Guzzi, D., 2004. Inquinamento atmosferico in aree urbane: Indici di qualità dell'aria. Chemical Engineering Thesis University of Naples "Federico II" Italy.

[6] Kassomenos, P., Skouloudis, A.N., Lykoudis, S., Flocas, H.A., 1999. “Airquality indicators" for uniform indexing of atmospheric pollution over large metropolitan areas. Atmospheric Environment 33, 1861-1879.

[7] Murena, F. Measuring air quality over large urban areas: development and application of an air pollution index at the urban area of Naples. Atmospheric Environment 2004, 38, 6195-6202.

[8] European Community, 1999. Council Directive 1999/30/EC of 22 April 1999 relating to limit values for sulphur dioxide, nitrogen dioxide and oxides of nitrogen, particulate matter and lead in ambient air. Official Journal L 163, 29/06/1999 P. 41-60.

[9] European Community, 2000. Directive 2000/69/EC of the European Parliament and of the Council of 16 November 2000 relating to limit values for benzene and carbon monoxide in ambient air. Official Journal L 313, 13/12/2000 P. 0012 - 0021.

[10] European Community, 2002. Directive 2002/3/EC of the European Parliament and of the Council of 12 February 2002 relating to ozone in ambient air. Official Journal L 67, 9/3/2002. P. 14-30. 
[11] Cairncross, E. K., John, J., Zunckel M., 2007. A novel air pollution index based on the relative risk of daily mortality associated with short-term exposure to common air pollutants. Atmospheric Environment 41, 84428454.

[12] Stieb D.M., Burnett R. T., Smith-Doiron, M., Brion, O., Shin H.H., and Economou V. 2008. "A New Multipollutant, No-Threshold Air Quality Health Index Based on Short-Term Associations Observed in Daily TimeSeries Analyses". Journal of the Air \& Waste Management Association 58: 435-450. 